\title{
Population Projection of the Districts Noakhali, Feni, Lakhshmipur and Comilla, Bangladesh by Using Logistic Growth Model
}

\author{
Tanjima Akhter, Jamal Hossain*, Salma Jahan \\ Department of Applied Mathematics, Noakhali Science and Technology University, Noakhali, Bangladesh \\ Email address: \\ tanjimatanju.bd@gmail.com (T. Akhter), z_math_du@yahoo.com (J. Hossain), salma.math@nstu.edu.bd (S. Jahan) \\ ${ }^{*}$ Corresponding author
}

\section{To cite this article:}

Tanjima Akhter, Jamal Hossain, Salma Jahan. Population Projection of the Districts Noakhali, Feni, Lakhshmipur and Comilla, Bangladesh by Using Logistic Growth Model. Pure and Applied Mathematics Journal. Vol. 6, No. 6, 2017, pp. 164-176.

doi: 10.11648/j.pamj.20170606.13

Received: October 28, 2017; Accepted: December 4, 2017; Published: January 2, 2018

\begin{abstract}
Uncontrolled human population growth has been posing a threat to the resources and habitats of Bangladesh. Population of different region of Bangladesh has been increasing dramatically. As a thriving country Bangladesh should artistically deal with this issue. This work is all about to estimate the population projection of the districts Noakhali, Feni, Lakhshmipur and Comilla, Bangladesh. By considering logistic growth model and making use of least square method and MATLAB to compute population growth rate and carrying capacity and the year when population will be nearly half of its carrying capacity and shown population projection for the above mentioned districts and give a comparison with actual population for the same time period. Also estimate future picture of population for these districts.
\end{abstract}

Keywords: Population, Carrying Capacity, Growth Rate, Vital Coefficient, Least Square Method

\section{Introduction}

Population projection is one of the most initiative concerns to assure rapid, effective and sustainable advancement for human. It is a useful tool to demonstrate the magnitude of current problems and likely to estimate the future magnitude of the problem. In rapidly changing current world, population projection has become one of the most momentous problems. Population size and growth in a country baldly influence the situation of policy, culture, education and environment etc of that country and cost of natural sources. Those resources can be exhausted because of population explosion but no one can wait till that. Therefore the study of population projection has started earlier. The projection of future population gives a future picture of population size which is controllable by reducing population growth with different possible measures. Changes in population size and composition have many social, environmental and political implications, for this reason population projection often serve as a basis for producing other projections (e.g. births, household, families, school). Every development plans contain future estimates of a nations need as well as for policy formulation for sectors such as labour force, urbanization, agriculture etc. Any native or central government's contribution can be extreme in performing task of long term effect if they have feasible statistics particularly with incontrovertible presumptive ulterior scenario of the concern demography. For maximal possible approximation mathematical and statistical analysis are required. Thus from analysis population projection can be done basing on the previous data. For such approach to get better result, mathematical modeling has become a broad interdisciplinary science that uses mathematical and computational techniques to model and elucidate the phenomena arising in life sciences. Effort in this work is to model the population growth pattern of Noakhali, Feni, Lakhsmipur \& Comilla using Logistic growth model. For the purpose of population modeling and forecasting in variety of fields, this model is widely used [1]. In wide range of cases in model the growth of various species, first order differential equations are very effective. As population of any species can never be a differentiable function of time, it would apparently impossible to mimic integer data of population 
with a differential equation of continuous variable. In case of a large population, if it is increased by one, then the change is very small compared to the given population [2]. Logistic model also tells that the population growth rate decreases as the population reaches the saturation point of the environment. In this paper, the governing entities i.e. the carrying capacity and the vital coefficients for the population growth were determined using the least square method.

\section{Development of Logistic Growth Model}

The mathematical model of population growth proposed by Thomas R. Malthus in 1798 is

$$
\frac{d}{d t} P(t)=a P(t)
$$

Equation (1) is a first order linear differential equation; representing population growth in this case has solution

$$
P(t)=P_{0} e^{a t}
$$

This is known as the solution of Malthusian growth model. According to ideal conception if the population continues to grow without bound nature will take over in the long run. In such a situation, birth rates tend to decline while death rates tend to increase for the limited food resource. As long as there are enough resources available, there will be an increase in the number of individuals, or a positive growth rate. As resources begin to slow down, hence a model incorporating carrying capacity, proposed by Belgian Mathematician Verhulst, is more reasonably considerable than Malthusian law. Logistic model illustrates how a population may increase exponentially until it reaches the carrying capacity of its environment. When a population reaches the carrying capacity, growth slows down or stops altogether. Verhulst showed that the population growth depends both on the population size and on how far this size is from its upper limit, i.e., its carrying capacity [3]. His modification of Malthus's model encompass an additional term $\frac{a-b P(t)}{a}$ where $a$ and $b$ are called the vital coefficients of the population [4]. Thus the modified equation is of the form.

$$
\frac{d}{d t} P(t)=\frac{a P(t)(a-b P(t))}{a}
$$

Equation (3) provides the right feedback to limit the population growth as the additional term will become very small and tend to zero as the population value grows and gets closer to $\frac{a}{b}$. Thus the second term reflecting the competition for available resources tends to constrain the population growth and consequently growth rate. The Verhulst's equation (3), widely known as the logistic law of population growth, is a nonlinear differential equation. Discarding t, equation (3) can be rewritten as

$$
\frac{d}{d t} P=a P-b P^{2}
$$

Separating the variables in equation (4) and integrating we obtain

$$
\int \frac{1}{a}\left(\frac{1}{P}+\frac{b}{a-b P^{2}}\right) d p=t+f
$$

So that

$$
\frac{1}{a}(\log P-\log (a-b p))=t+f
$$

Using $t=0$ and $P=P_{0}$, we see that

$$
f=\frac{1}{a}\left(\log P_{0}-\log \left(a-b P_{0}\right)\right)
$$

Equation (5) becomes

$$
\frac{1}{a}(\log P-\log (a-b P))=t+\frac{1}{a}\left(\log P_{0}-\log \left(a-b P_{0}\right)\right)
$$

Solving for $P$ yields

$$
P=\frac{\frac{a}{b}}{1+\left(\frac{\frac{a}{b}}{P_{0}}-1\right) e^{-a t}}
$$

If we take the limit of equation (6) as $t \rightarrow \infty$, we get (since $a>0$ )

$$
P_{\max }=\lim _{t \rightarrow \infty} P=\frac{a}{b}
$$

Then the value of $a, b$ and $P_{\max }$ were determined by using the least square method. Differentiation of equation (6) twice with respect to $t$ gives

$$
\frac{d^{2} P}{d t^{2}}=\frac{F a^{3} e^{a t}\left(F-e^{a t}\right)}{b\left(F+e^{a t}\right)^{3}}
$$

where $F=\frac{\frac{a}{b}}{P_{0}}-1$.

Since at the inflection point, the equation (8) representing second derivative of $P$ must be equal to zero. This is possible if

$$
\begin{aligned}
& F=e^{a t} \\
& t=\frac{\ln F}{a}
\end{aligned}
$$


For this value of $t$ or time the point of inflection occurs, that is, when the population is a half of the value of its carrying capacity. Hence, the coordinate of the point of inflection is $\left(\frac{\ln F}{a}, \frac{L}{2}\right)$. If the time when the point of inflection occurs is $t=t_{i}$, then $F=e^{a t}$ becomes $F=e^{a t_{i}}$. If we use this new value of $F$ and replace $\frac{a}{b}$ by $L$, then equation (6) will be

$$
P=\frac{L}{1+e^{-a\left(t-t_{i}\right)}}
$$

Let coordinates of the actual and that of the predicted population values be $(t, m)$ and $(t, M)$ respectively with the same abscissa which can be presented in the same figure. $(M-m)$ indicates the error in this case. To ensure that error is positive, we square $(M-m)$. Thus, for curve fitting, total squared error denoted by $l$ has the form

$$
l=\sum_{j=1}^{m}\left(M_{j}-m_{j}\right)^{2}
$$

It is clear that equation (12) in connection with equation (11) contains three parameters $M, a$ and $t_{i}$. To eliminate $L$ we let

$$
P=L h
$$

To get equation (11) as

$$
h=\frac{1}{1+e^{-a\left(t-t_{i}\right)}}
$$

In equation (12), using the value of $P$ from equation (13) and by properties of inner product, we get,

$$
\begin{aligned}
& l=\sum_{j=1}^{m}\left(M_{j}-m_{j}\right)^{2}=\left(M_{j}-m_{j}\right)^{2}+\cdots+\left(M_{n}-m_{n}\right)^{2} \\
&=\left(L h_{1}-m_{1}\right)^{2}+\cdots+\left(L h_{n}-m_{n}\right)^{2}=\left|\left(L h_{1}-m_{1}, \ldots L h_{n}-m_{n}\right)\right|^{2} \\
&=\left|\left(L h_{1}, \ldots L h_{n}\right)-\left(m_{1}, \ldots m_{n}\right)\right|^{2}=|L H-G|^{2} \\
&= L^{2}\langle H, H\rangle-2 L\langle H, G\rangle+\langle G, G\rangle \\
& \text { where } H=h_{1}, h_{2}, \ldots h_{n} \text { and } G=m_{1}, m_{2}, \ldots m_{n} \text { Thus }
\end{aligned}
$$

$$
l=L^{2}\langle H, H\rangle-2 L\langle H, G\rangle+\langle G, G\rangle(15)
$$

Differentiating $l$ once with respect to $L$ partially and equating it to zero, we get

$$
2 L\langle H, H\rangle-2\langle H, G\rangle=0
$$

This gives,

$$
L=\frac{\langle H, G\rangle}{\langle H, H\rangle}
$$

From equation (13) by substituting this value of $L$, we obtain

$$
l=\langle G, G\rangle-\frac{\langle H, G\rangle^{2}}{\langle H, H\rangle}
$$

The equation (17) is an error function that containing just two parameters $a$ and $t_{i}$ which are determined by MATLAB program. The values of the parameters were in equation (16) to get the value of $L$.

\section{Results}

\subsection{Population Projection of Noakhali District Using Logistic Growth Model}

We find that values of $a$ and $t_{i}$ are 0.018 and 2215 respectively using actual population values, their corresponding years from Table 1 and using MATLAB programs. Thus, the population growth rate of Noakhali is nearly $1.8 \%$ per annum and population size will be a half of its limiting value or carrying capacity in the year 2215. From equation (20) by using values of $a$ and $t_{i}$ and MATLAB program, we get

$$
L=P_{\max }=124759666.50
$$

This is the predicted limiting value of the population of Noakhali. Then, equation (7) gives

$$
b=\frac{0.018}{124759666.50}=1.44 \times 10^{-10}
$$

The initial population will be $P_{0}=2577244$, if we let $t=0$ to correspond to the year 2001. Substituting the values of $P_{0}, \frac{a}{b}$ and $a$ into equation (6), we get

$$
P=\frac{124759666.50}{1+47.50 e^{-0.018 t}}
$$

To compute the predicted values of the population, the equation (20) was used. The time at the point of inflection is found from equation (10) by using values of $a, b$ and $P_{0}$ and it is

$$
t \approx 214
$$

This value when added to the actual year corresponding to $t=0$, i.e., 2001 gives 2215 as earlier found as the value of $t_{i}$. From equation (20) by using this value of $t$, we obtain

$$
\frac{a}{2 b}=62379833.3
$$


Thus, in the year 2215 the population of Noakhali district is predicted to be 62379833.3 which is a half of its carrying capacity. The table below shows predicted and their corresponding actual population values:

Table 1. Actual and predicted values of population of Noakhali.

\begin{tabular}{llllllll}
\hline Year & Actual Population & Growth Rate & Predicted Population & Year & Actual Population & Growth Rate & Predicted Population \\
\hline 2001 & 2577244 & 1.52 & 2577244 & 2008 & 2935999 & 1.97 \\
2002 & 2621830 & 1.73 & 2623070 & 2009 & 2993545 & 1.96 \\
2003 & 2670334 & 1.85 & 2669694 & 2010 & 3051320 & 1.93 \\
2004 & 2720349 & 1.87 & 2717127 & 2011 & 3108083 & 1.86 \\
2005 & 2771818 & 1.89 & 2765384 & 2012 & 3164028 & 1.80 \\
2006 & 2825314 & 1.93 & 2814479 & 2013 & 3219715 & 360925 \\
2007 & 2879278 & 1.91 & 2864424 & 2014 & 3273806 & 319 & 1.76 \\
\hline
\end{tabular}

Source: "Population and Housing Census 2011, Zilla Report: Noakhali”, Bangladesh Statistical Bureau, Bangladesh [5].

The following is the graph of actual population and predicted population values against time.

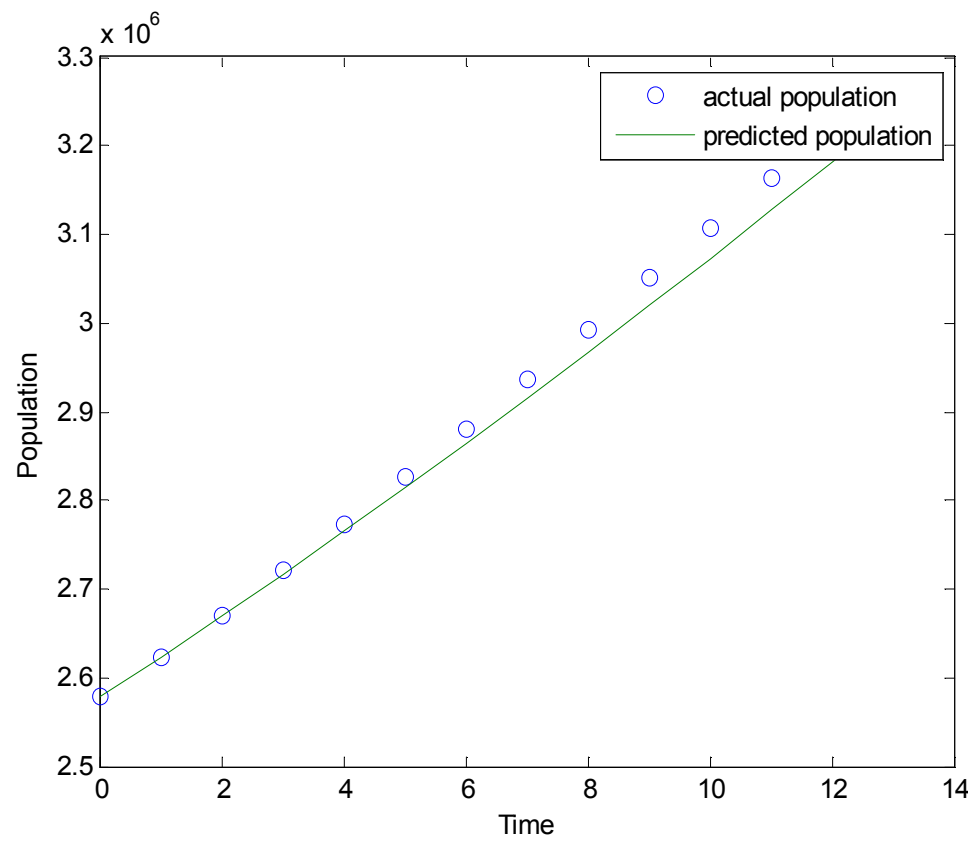

Figure 1. Graph of actual population and predicted population values against.

Below is the graph of predicted population values against time. Equation (20) was used to compute the values.

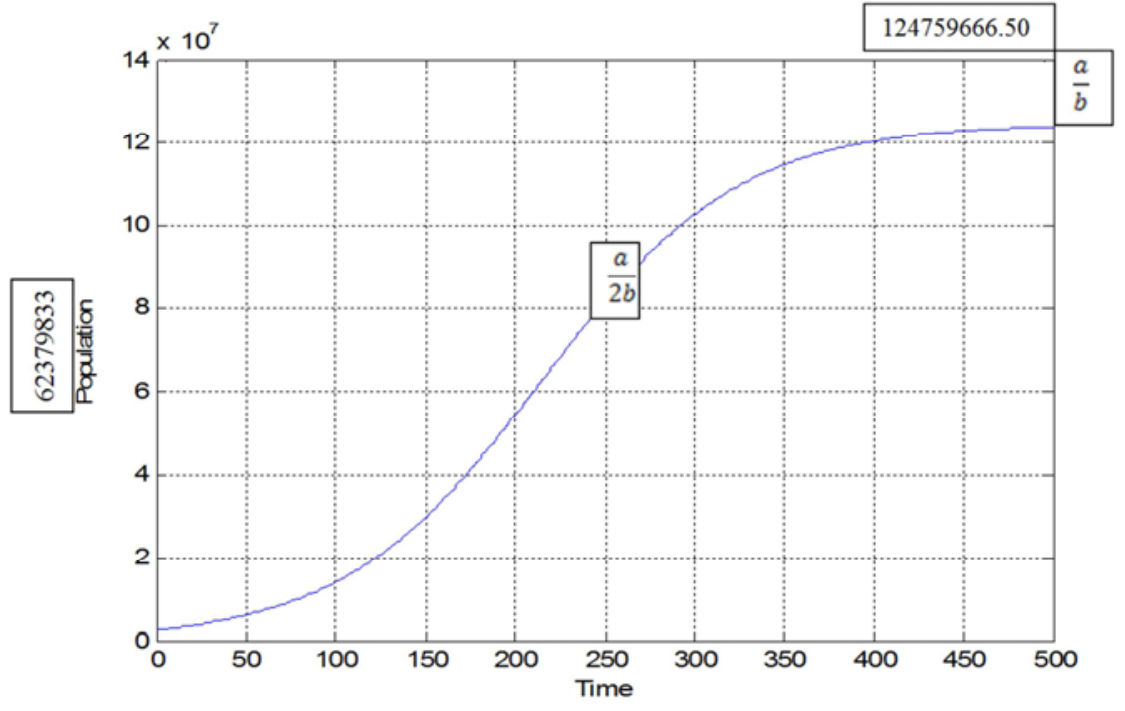

Figure 2. Graph of predicted population values against time. 


\subsection{Population Projection of Feni District Using Logistic Growth Model}

We find that the values of $a$ and $t_{i}$ are 0.014 and 2295 respectively by using actual population values, their corresponding years from Table 2 and using MATLAB programs. Thus, the value of the population growth rate of Feni is nearly $1.4 \%$ per annum and the population size will be a half of its limiting value or carrying capacity in the year 22195.

From equation (16) by using values of $a$ and $t_{i}$ and MATLAB program, we get

$$
L=P_{\max }=77708419 \cdot 91
$$

This is the predicted limiting value of the population of Feni. Then, equation (11) gives

$$
b=\frac{0.014}{77708419.91}=1.80 \times 10^{-10}
$$

The initial population will be $P_{0}=1240384$, if we let $t=0$ to correspond to the year 2001. Substituting the values of $P_{0}, \frac{a}{b}$ and $a$ into equation (6), we get

$$
P=\frac{77708419.91}{1+61.7 e^{-0.014 t}}
$$

To compute the predicted values of the population, the equation (24) was used. The time at the point of inflection is found from equation (10) by using values of $a, b$ and $P_{0}$ and it is

$$
t \approx 294
$$

This value when added to the actual year corresponding to $t=0$, i.e., 2001 gives 2295 as earlier found as the value of $t_{i}$. From equation (24) by using this value of $t$, we obtain

$$
\frac{a}{2 b}=38854210
$$

Thus, in the year 2295 the population of Feni district is

\begin{tabular}{|c|c|c|c|c|c|c|c|}
\hline Year & Actual Population & Growth Rate & Predicted Population & Year & Actual Population & Growth Rate & Predicted Population \\
\hline 2001 & 1240384 & 1.24 & 1240384 & 2008 & 1376208 & 1.68 & 1365853 \\
\hline 2002 & 1256509 & 1.30 & 1257589 & 2009 & 1396714 & 1.49 & 1384766 \\
\hline 2003 & 1273598 & 1.36 & 1275028 & 2010 & 1416687 & 1.43 & 1403936 \\
\hline 2005 & 1310788 & 1.48 & 1310622 & 2012 & 1457494 & 1.40 & 1443062 \\
\hline 2006 & 1331630 & 1.59 & 1328784 & 2013 & 1477462 & 1.37 & 1463024 \\
\hline 2007 & 1353469 & 1.64 & 1347193 & 2014 & 1497260 & 1.34 & 1483256 \\
\hline
\end{tabular}
predicted to be 38854210 which is a half of its carrying capacity. The table below shows the predicted population values and their corresponding actual population values.

Table 2. Actual and predicted values of population of Feni.

Source: "Population and Housing Census 2011, Zilla Report: Feni”, Bangladesh Statistical Bureau, Bangladesh [6].

The following is the graph of actual population and predicted population values against time.

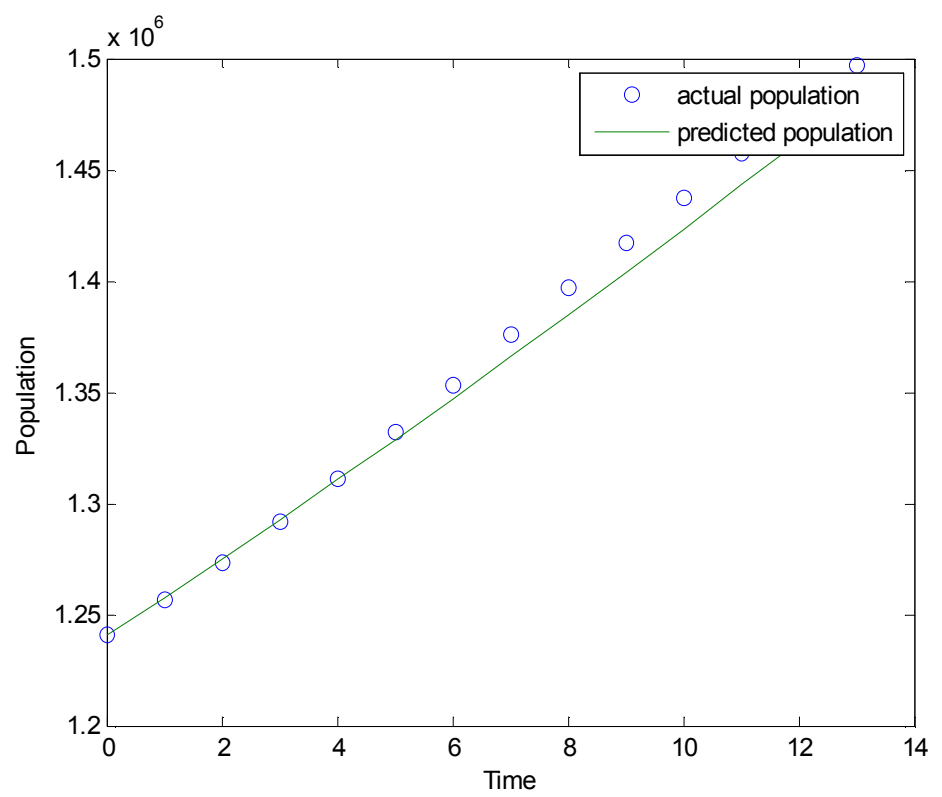

Figure 3. Graph of actual population and predicted population values against time. 
Below is the graph of predicted population values against time. Equation (24) was used to compute the values

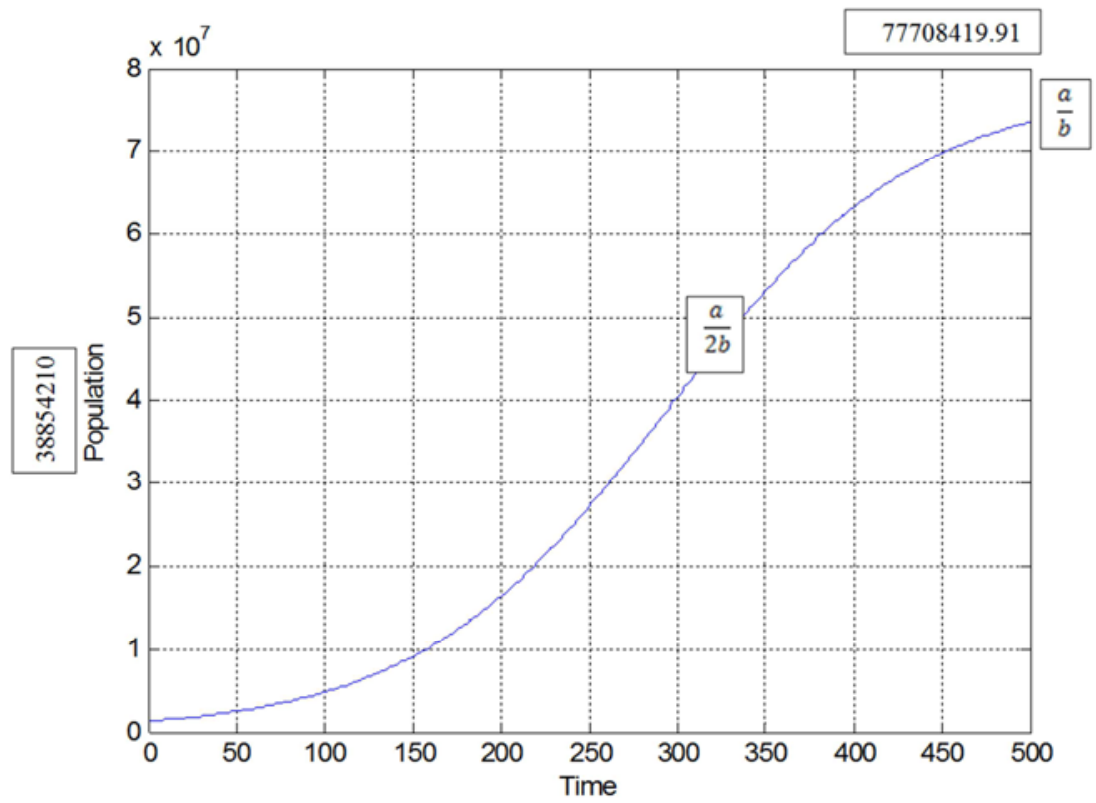

Figure 4. Graph of predicted population values against time.

\subsection{Population Projection of Lakhshmipur District Using Logistic Growth Model}

We find that the values of $a$ and $t_{i}$ are 0.015 and 2275 respectively by using actual population values, their corresponding years from Table 3 and using MATLAB programs. Thus, the value of the population growth rate of Lakhshmipur is nearly $1.5 \%$ per annum and the population size will be a half of its limiting value or carrying capacity in the year 2275. From equation (16) by using values of $a$ and $t_{i}$ and MATLAB program, we get

$$
L=P_{\max }=92301500.58
$$

This is the predicted limiting value of the population of Lakhshmipur. Then, equation (11) gives

$$
b=\frac{0.015}{92301500.58}=1.63 \times 10^{-10}
$$

The initial population will be $P_{0}=1489901$, if we let $t=0$ to correspond to the year 2001. Substituting the values of $P_{0}, \frac{a}{b}$ and $a$ into equation (6), we get

$$
P=\frac{92301500.58}{1+60.77 e^{-0.015 t}}
$$

To compute the predicted values of the population, the equation (28) was used. The time at the point of inflection is found from equation (10) by using values of $a, b$ and $P_{0}$ and it is

$$
t \approx 274
$$

This value when added to the actual year corresponding to $t=0$, i.e., 2001 gives 2275 as earlier found as the value of $t_{i}$. From equation (28) by using this value of $t$, we obtain

$$
\frac{a}{2 b}=46150750
$$

Thus, in the year 2275 the population of Lakhshmipur district is predicted to be 46150750 which is a half of its carrying capacity. The table below shows the predicted population values and their corresponding actual population values.

Table 3. Actual and predicted values of population of Lakhshmipur.

\begin{tabular}{llllllll}
\hline Year & Actual Population & Growth Rate & Predicted Population & Year & Actual Population & Growth Rate & Predicted Population \\
\hline 2001 & 1489901 & 1.28 & 1489901 & 2008 & 1651376 & 1.57 \\
2002 & 1513441 & 1.58 & 1512049 & 2009 & 1678293 & 1.63 \\
2003 & 1535176 & 1.44 & 1534521 & 2010 & 1703970 & 1.53 \\
2004 & 1556361 & 1.38 & 1557321 & 2011 & 1729188 & 1.48 \\
2005 & 1578617 & 1.43 & 1580454 & 2012 & 1754261 & 1.45 \\
2006 & 1601823 & 1.47 & 1603924 & 2013 & 1779172 & 1704 \\
2007 & 1625850 & 1.50 & 1627737 & 2014 & 1803902 & 1.42 \\
\hline
\end{tabular}

Source: "Population and Housing Census 2011, Zilla Report: Lakhshmipur", Bangladesh Statistical Bureau, Bangladesh [7]. 
The following is the graph of actual population and predicted population values against time.

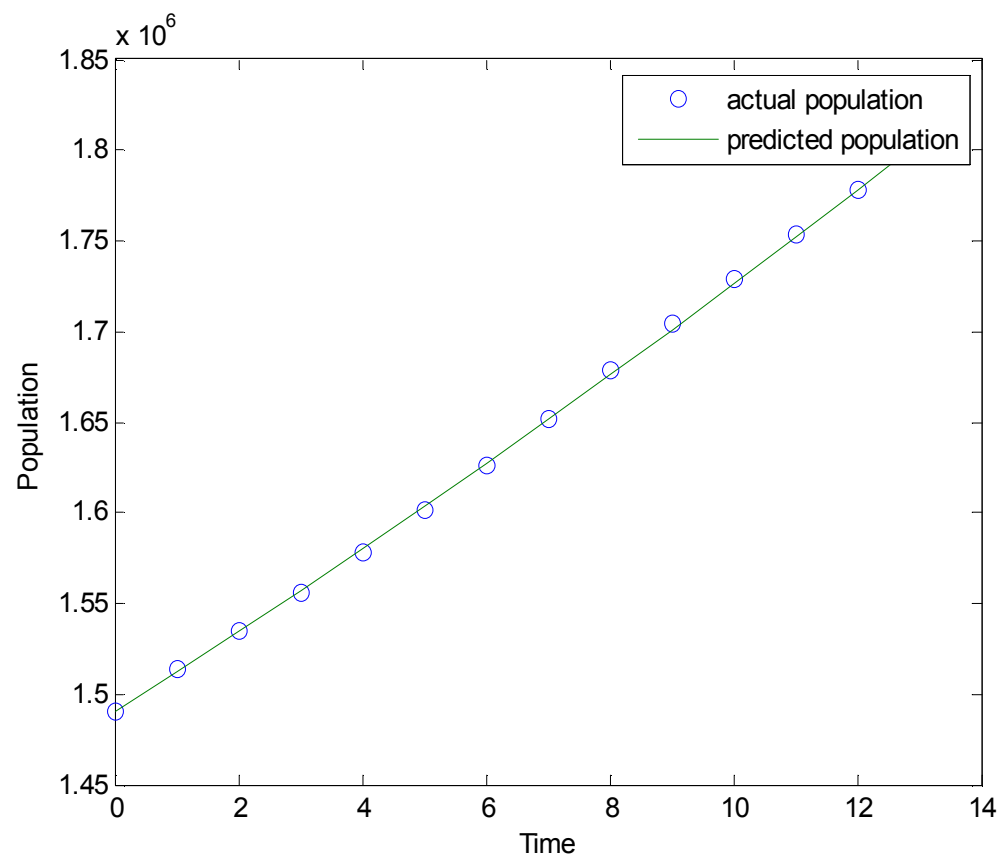

Figure 5. Graph of actual population and predicted population values against time.

Below is the graph of predicted population values against time. Equation (28) was used to compute the values

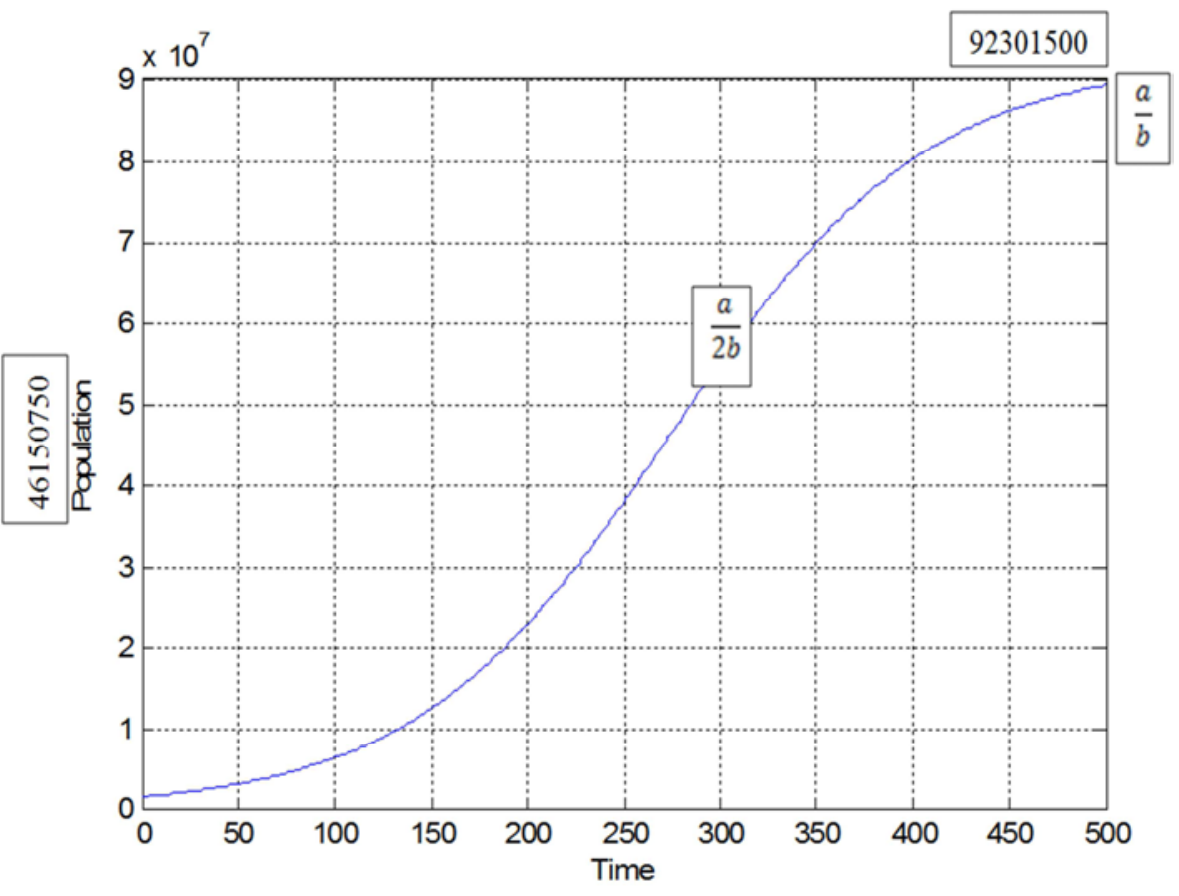

Figure 6. Graph of predicted population values against time.

\subsection{Population Projection of Comilla District Using Logistic Model}

We find that values of $a$ and $t_{i}$ are 0.016 and 2205 respectively using actual population values, their corresponding years from Table 4 and using MATLAB. Thus, the value of the population growth rate of Comilla is nearly $1.6 \%$ per annum and the population size will be a half of its limiting value or carrying capacity in the year 2205. From equation (20) using values of $a$ and $t_{i}$ and MATLAB program, we get 


$$
L=P_{\max }=125050091.07
$$

This is the predicted limiting value of the population of Comilla. Then, equation (11) gives

$$
b=\frac{0.016}{125050091.07}=1.28 \times 10^{-10}
$$

The initial population will be $P_{0}=4595557$, if we let $t=0$ to correspond to the year 2001. Substituting the values $P_{0}, \frac{a}{b}$ and $a$ into equation (6), we get

$$
P=\frac{125050091.07}{1+26.2 e^{-0.016 t}}
$$

To compute the predicted values of the population, the equation (32) was used. The time at the point of inflection is found from equation (10) by using values of $a, b$ and $P_{0}$ and it is

$$
t \approx 204
$$

This value when added to the actual year corresponding to $t=0$, i.e., 2001 gives 2205 as earlier found as the value of $t_{i}$. From equation (32) by using this value of $t$, we obtain

$$
\frac{a}{2 b}=62525046
$$

Thus, in the year 2205 the population of Comilla district is

\begin{tabular}{|c|c|c|c|c|c|c|c|}
\hline Year & Actual Population & Natural Growth & Predicted Population & Year & Actual Population & Natural Growth & Predicted Population \\
\hline 2001 & 4595557 & 1.32 & 4595557 & 2008 & 5132212 & 1.73 & 5117900 \\
\hline 2002 & 4658057 & 1.36 & 466611 & 2009 & 5218433 & 1.68 & 5197014 \\
\hline 2003 & 4726530 & 1.47 & 4739330 & 2010 & 5303493 & 1.63 & 5277298 \\
\hline 2004 & 4801682 & 1.59 & 4812827 & 2011 & 5387288 & 1.58 & 5358766 \\
\hline 2005 & 4879604 & 1.62 & 4887417 & 2012 & 5470791 & 1.55 & 5441435 \\
\hline 2006 & 4961093 & 1.67 & 4963116 & 2013 & 5553947 & 1.52 & 5525320 \\
\hline 2007 & 5044935 & 1.69 & 5039939 & 2014 & 5636701 & 1.49 & 5610438 \\
\hline
\end{tabular}
predicted to be 62525046 which is a half of its carrying capacity. The table below shows the predicted population values and their corresponding actual population values.

Table 4. Actual and predicted values of population of Comilla.

Source: "Population and Housing Census 2011, Zilla Report: Comilla", BangladeshStatistical Bureau, Bangladesh [8].

The following is the graph of actual population and predicted population values against time.

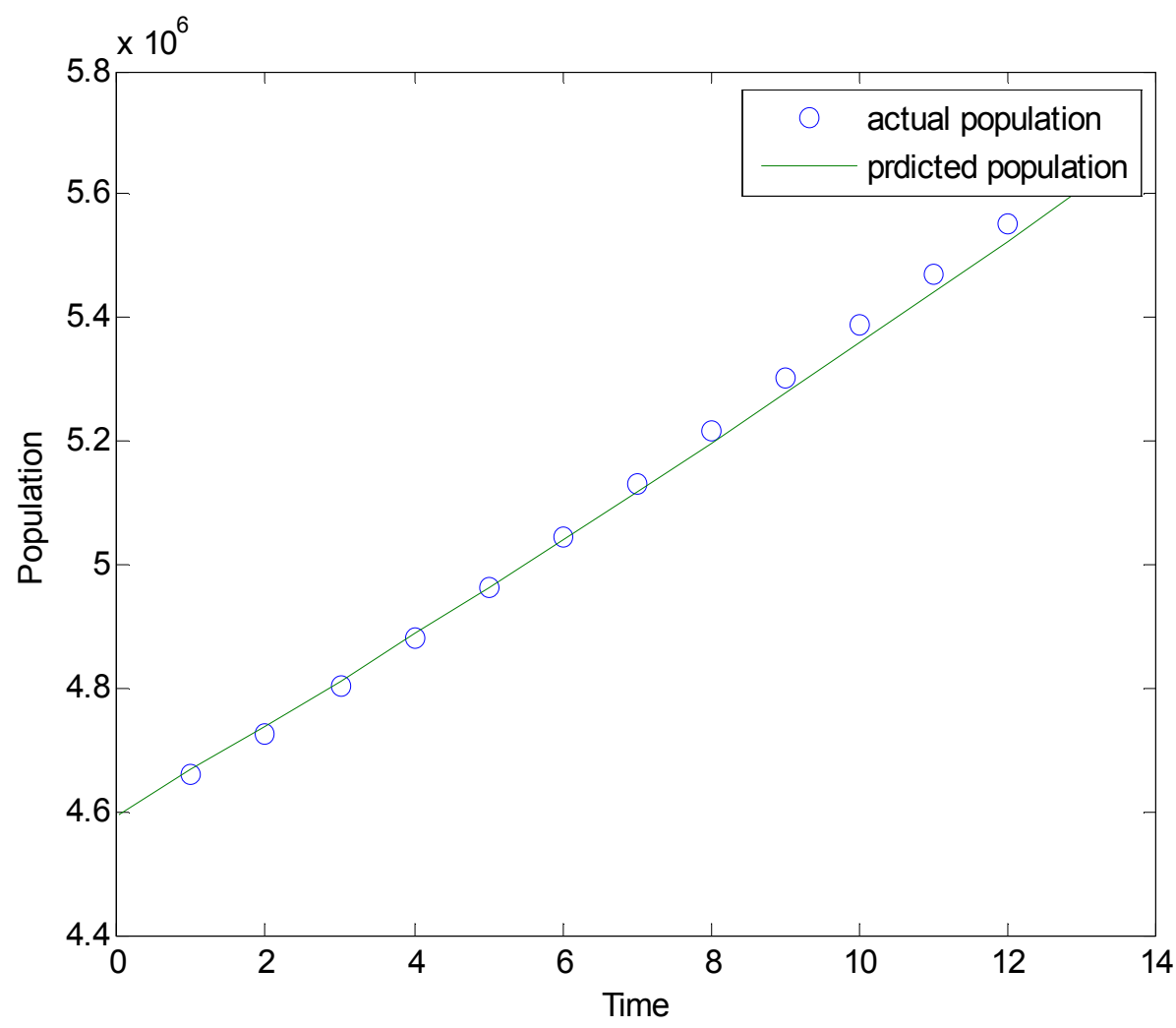

Figure 7. Graph of actual population and predicted population values against time.

Below is the graph of predicted population values against time. Equation (32) was used to compute the values 


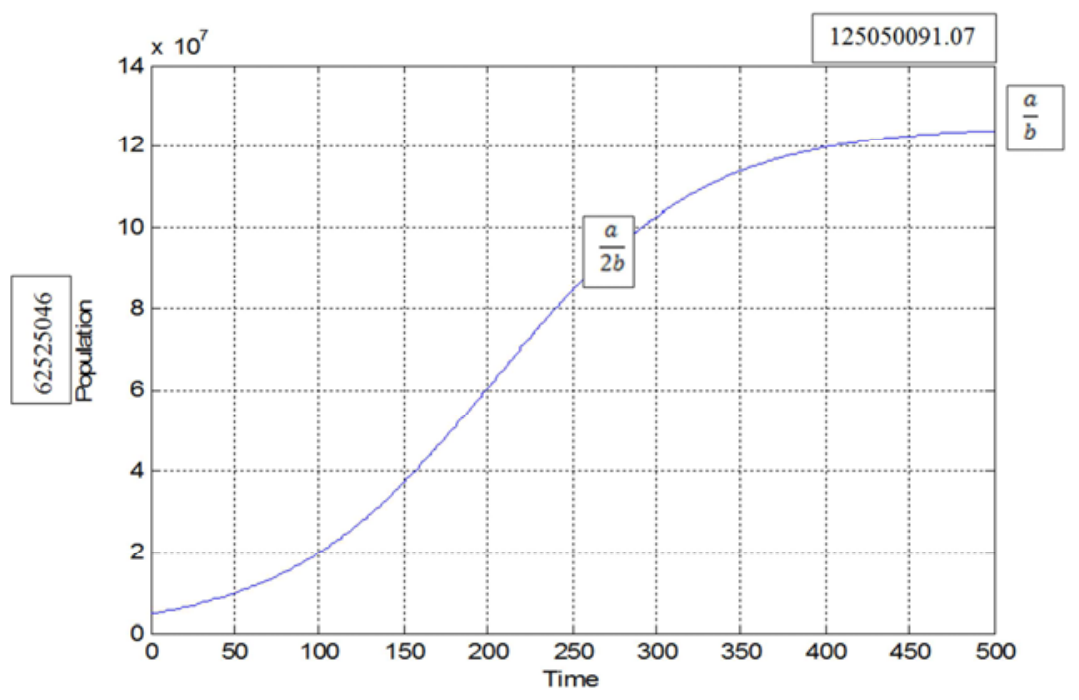

Figure 8. Graph of predicted population values against time.

\subsection{Estimation for Future Population of Noakhali Using Logistic Growth Model}

As equation (20) is the general solution, we use this to predict population of Noakhali from 2015 to 2040

Table 5. Predicted population of Noakhali.

\begin{tabular}{llll}
\hline Year & Predicted Population & Year & Predicted population \\
\hline 2015 & 3296356 & 2028 & 4136607 \\
2016 & 3354618 & 2029 & 4209205 \\
2017 & 3413881 & 2030 & 4283032 \\
2018 & 3474160 & 2031 & 4358107 \\
2019 & 3535473 & 2032 & 4434450 \\
2020 & 3597836 & 2033 & 4512080 \\
2021 & 3661266 & 2034 & 4591017 \\
2022 & 3725779 & 2035 & 4671281 \\
2023 & 3791394 & 2036 & 4752894 \\
2024 & 3858127 & 2037 & 4835874 \\
2025 & 3925997 & 2038 & 4920244 \\
2026 & 3995022 & 2039 & 5006024 \\
2027 & 4065219 & 2040 & 5093237 \\
\hline
\end{tabular}

Below is the graph of Predicted Population from 2015 to 2040 against time. Equation (20) was used to the compute the values

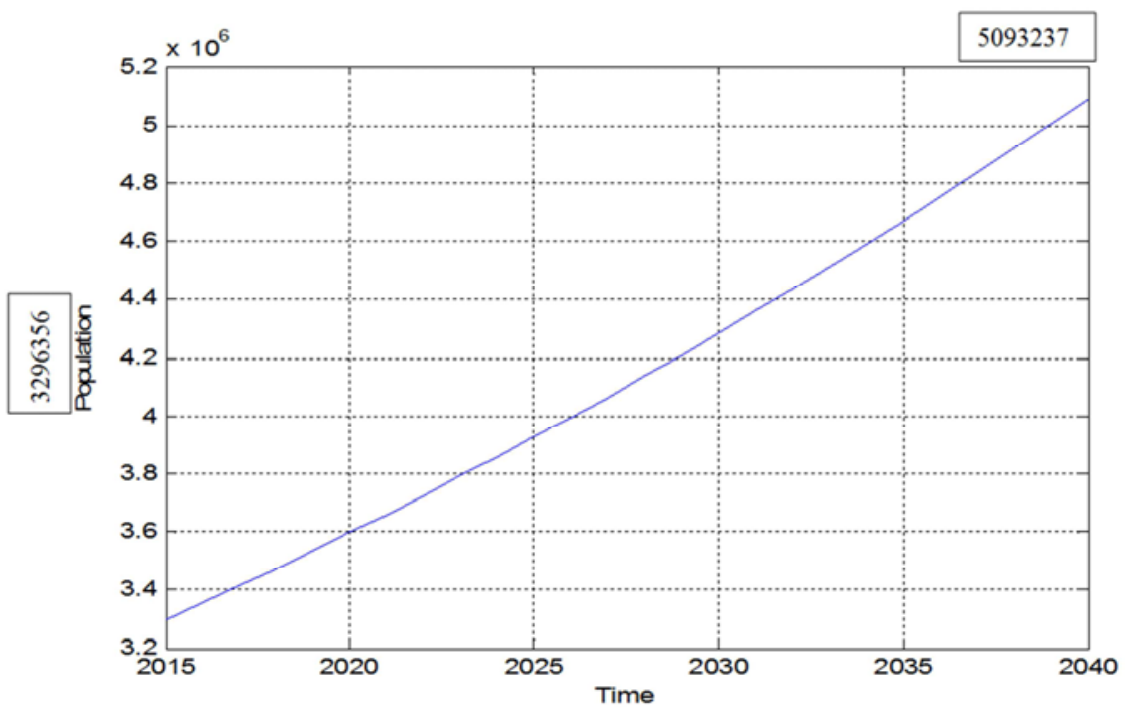

Figure 9. Graph of predicted population values against time. 


\subsection{Estimation for Future Population of Feni Using Logistic Growth Model}

As equation (24) is the general solution, we use this to predict population of Feni from 2015 to 2040

Table 6. Predicted population of Feni.

\begin{tabular}{llll}
\hline Year & Predicted Population & Year & Predicted Population \\
\hline 2015 & 1503763 & 2028 & 1796994 \\
2016 & 1524548 & 2029 & 1821735 \\
2017 & 1545614 & 2030 & 1846808 \\
2018 & 1566966 & 2031 & 1872218 \\
2019 & 1588606 & 2032 & 1897969 \\
2020 & 1610539 & 2033 & 1924065 \\
2021 & 1632768 & 2034 & 1950510 \\
2022 & 1655297 & 2035 & 1977310 \\
2023 & 1678130 & 2036 & 2004468 \\
2024 & 1701271 & 2037 & 2031989 \\
2025 & 1724724 & 2038 & 2059877 \\
2026 & 1748493 & 2039 & 2088138 \\
2027 & 1772581 & 2040 & 2116776 \\
\hline
\end{tabular}

Below is the graph of Predicted Population from 2015 to 2040 against time. Equation (24) was used to the compute the values

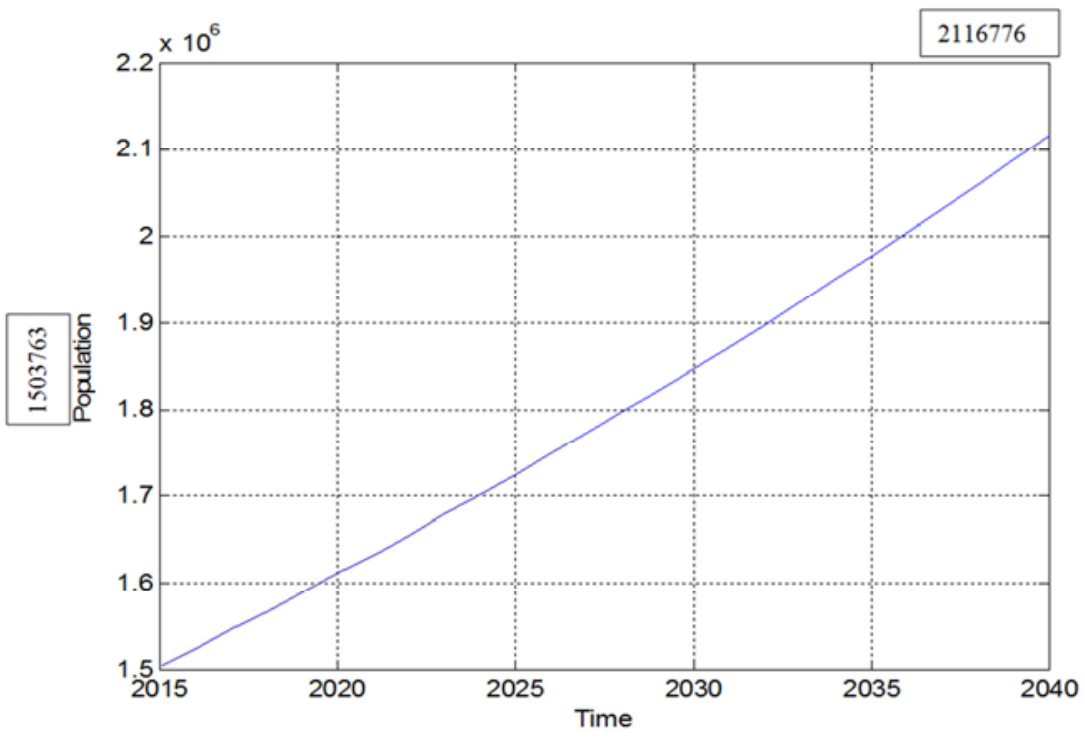

Figure 10. Graph of predicted population values against time.

\subsection{Estimation for Future Population of Lakhshmipur Using Logistic Growth Model}

As equation (28) is the general solution, we use this to predict population of Lakhshmipur from 2015 to 2040

Table 7. Predicted population of Lakhshmipur.

\begin{tabular}{llll}
\hline Year & Predicted Population & Year & Predicted Population \\
\hline 2015 & 1831151 & 2028 & 2215953 \\
2016 & 1858268 & 2029 & 2248627 \\
2017 & 1885779 & 2030 & 2281770 \\
2018 & 1913688 & 2031 & 2315390 \\
2019 & 1942001 & 2032 & 2349492 \\
2020 & 1970724 & 2033 & 2384082 \\
2021 & 1999862 & 2034 & 2419169 \\
2022 & 2029422 & 2035 & 2454758 \\
2023 & 2059408 & 2036 & 2490855 \\
2024 & 2089827 & 2037 & 2527469 \\
2025 & 2120685 & 2038 & 2564605 \\
2026 & 2151988 & 2039 & 2602272 \\
2027 & 2183942 & 2040 & 2640475 \\
\hline
\end{tabular}


Below is the graph of Predicted Population from 2015 to 2040 against time. Equation (28) was used to the compute the values

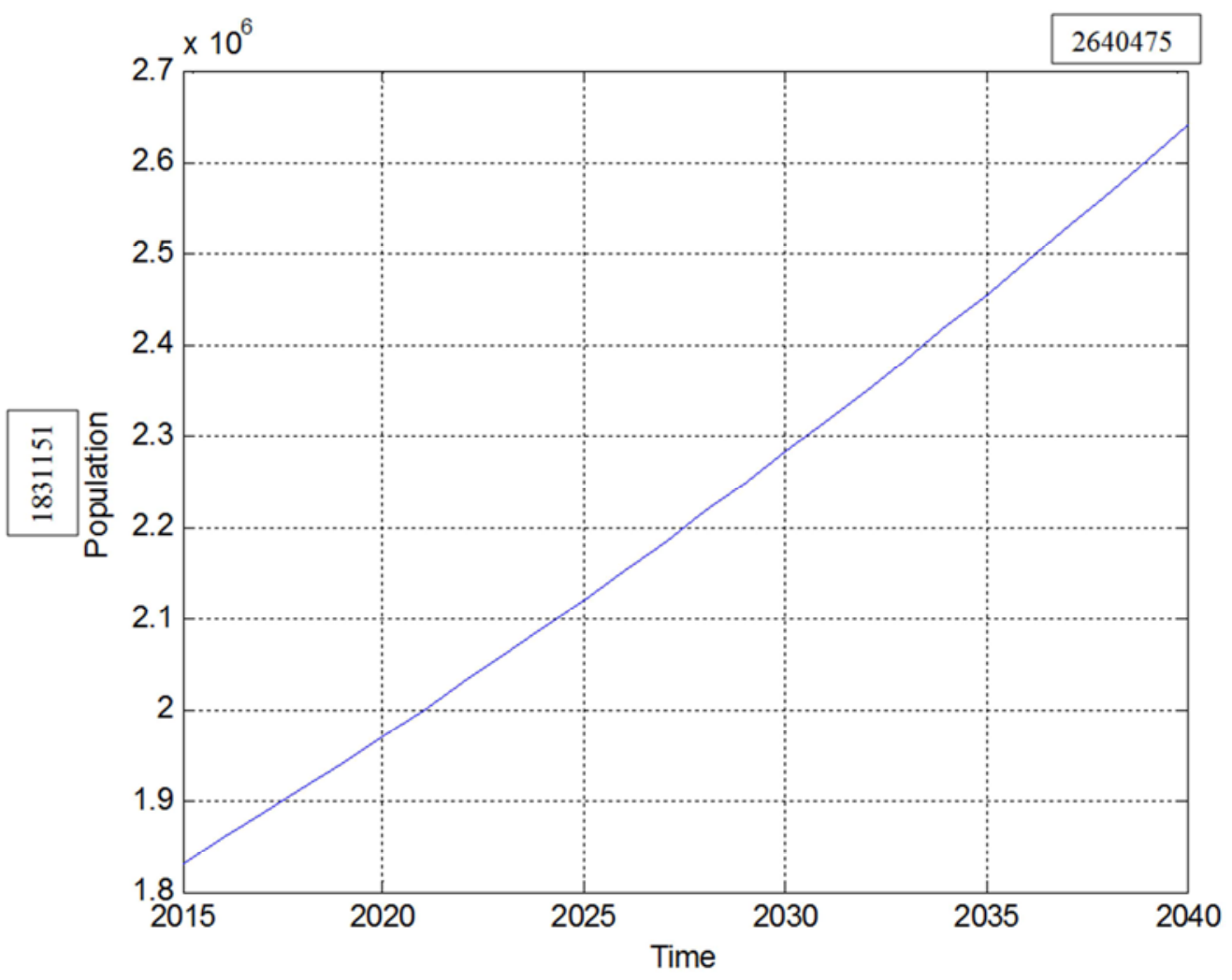

Figure 11. Graph of predicted population values against time.

\subsection{Estimation for Future Population of Comilla Using Logistic Growth Model}

As equation (32) is the general solution, we use this to predict population of Comilla from 2015 to 2040

Table 8. Predicted population of Comilla.

\begin{tabular}{llll}
\hline Year & Predicted Population & Year & Predicted Population \\
\hline 2015 & 5696805 & 2028 & 6940872 \\
2016 & 5784437 & 2029 & 7046511 \\
2017 & 5873350 & 2030 & 7153660 \\
2018 & 5963562 & 2031 & 7262339 \\
2019 & 6055089 & 2032 & 7372565 \\
2020 & 6147948 & 2033 & 7484358 \\
2021 & 6242157 & 2034 & 7597736 \\
2022 & 6337732 & 2035 & 7712720 \\
2023 & 6434692 & 2036 & 7829328 \\
2024 & 6533053 & 2037 & 7947579 \\
2025 & 6632833 & 2038 & 8067493 \\
2026 & 6734051 & 2039 & 8189090 \\
2027 & 6836725 & 2040 & 8312390 \\
\hline
\end{tabular}

Below is the graph of Predicted Population from 2015 to 2040 against time. Equation (32) was used to the compute the values 


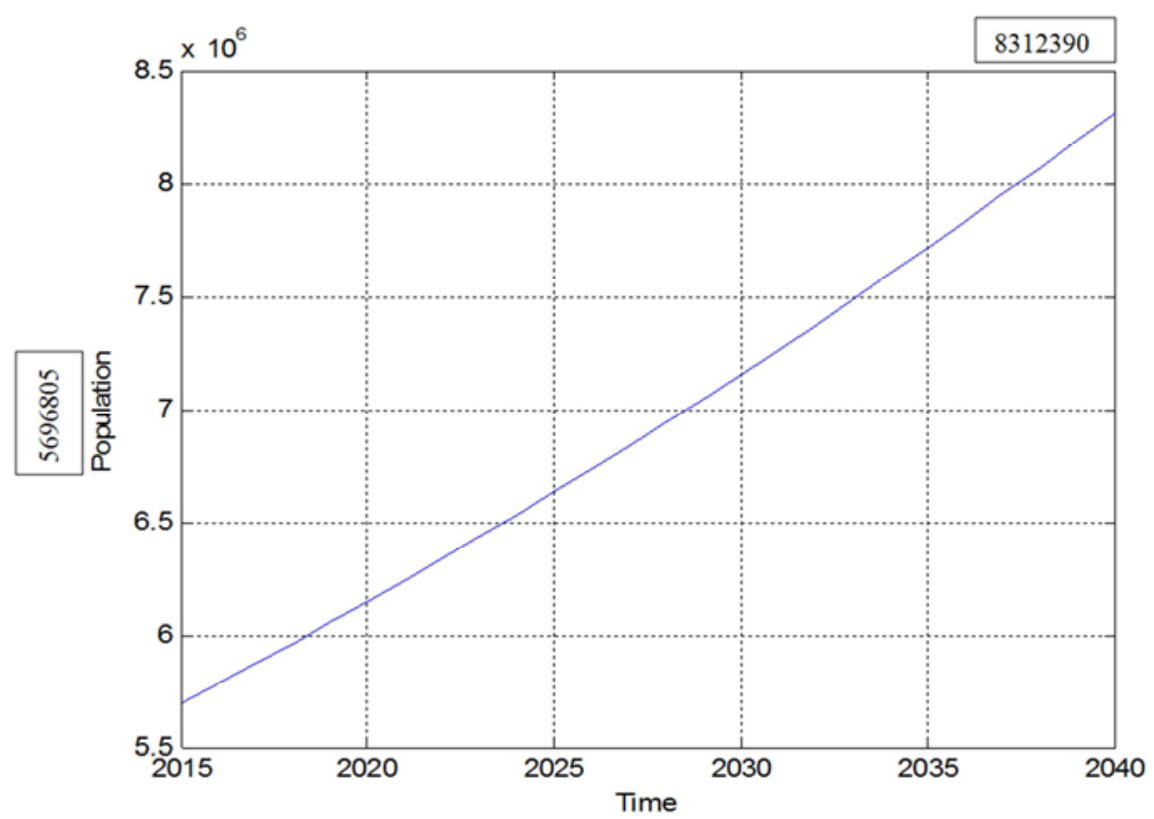

Figure 12. Graph of predicted population values against time.

\section{Discussion}

In Figure 1, 3, $5 \& 7$ the actual and predicted values of population predicted by Logistic Model of the districts Noakhai, Feni, Lakhshmipur \& Comilla are quite close to one another. This indicates that errors between them are very small. We can also see in Figure 2, 4, $6 \& 8$ that graph of predicted population values are fitted well into the Logistic curve. In case of Noakhali district population starts to grow going through an exponential growth phase reaching 62379833 (a half of its carrying capacity) in the year 2215 after which the rate of growth is expected to slow down. As it gets closer to the carrying capacity, 124759666.50 the growth is again expected to drastically slow down and reach a stable level. Population growth rate of Noakhali according to information in Bangladesh statistical bureau was around $1.5 \%, 1.7 \%$ in $2001,2002 \&$ and $1.9 \%$ in $2003,2004,2005$ which corresponds well with the findings in this research work of a growth rate of approximately $1.8 \%$ per annum. Population of Feni tends to grow until it reaches 38854210 in year 2295 then rate of growth drop off. As it come closer to carrying capacity, 77708419.91 the growth is again acutely slow down and become static. Feni's population growth rate corresponds to data in Bangladesh statistical bureau was closely $1.2 \%, 1.3 \%, 1.4 \%, 1.4 \%$ in $2001,2002,2003$ and 2004 which are identical with the findings of a growth rate of proximately $1.4 \%$ per annum. In Lakhshmipur district population rise up to 46150750 exponentially in year 2275 after which growth rate slack off. As the population approaching the carrying capacity, 92301500.58 the growth is again supposed to excessively slow down and catch up to a stable state. The population growth rate of Lakhshmipur following to information in Bangladesh statistical bureau was approximately $1.3 \%, 1.6 \%$ in 2001,2002 , and $1.4 \%$ in 2003 , 2004, 2005 which are similar to the findings in this work of a growth rate of about $1.5 \%$ per annum. Comilla's population starts to grow through a Malthusian growth when it reaches 62525046 in year 2205 growth rate gradually decline. As it appears nearer to carrying capacity, 125050091.07 the growth is again severely slow down and come up to an invariable sate. Regarding to data of Bangladesh statistical bureau Comilla's growth rate was approximately $1.3 \%, 1.4 \%$, $1.4 \%, 1.6 \%, 1.6 \%$ in $2001,2002,2003,2004,2005$ which are consistent with the findings in this paper of a growth rate of nearly $1.6 \%$ per annum. The Logistic growth model projected Noakhali, Feni, Lakhshmipur \& Comilla's population in 2040 to be 5093237, 2116776, 2640475 \& 8312390. Population predicted by Logistic model of above mentioned districts from 2015 to 2040 are presented in figure 9, 10, 11 and 12 respectively.

\section{Conclusions}

Logistic model predicted a carrying capacity for the population of Noakhali to be 124759666.50 . Population growth of any country depends also on the vital coefficients. The vital coefficients $\mathrm{a}, \mathrm{b}$ are respectively 0.018 and $1.44 \times 10^{-10}$. Thus the population growth rate of Noakhali, according to this modelis $1.8 \%$ per annum. This approximated population growth rate compares well with the statistically predicted values in literature. Based on this model the population of Noakhali is expected to be 62379833 (a half of its carrying capacity) in the year 2215. Logistic growth model estimated a carrying capacity for the population of Feni to be 77708419.91 . Here the vital coefficients $\mathrm{a}, \mathrm{b}$ are respectively 0.014 and $1.8 \times 10^{-10}$. Thus the population growth rate of Feni, according to this model is $1.4 \%$ per annum. Based on this model the population of Feni is supposed to be 38854210 (half of carrying capacity) in the year 2295. For Lakhshmipur district carrying capacity predicted by Logistic growth model is 92301500.58 and the 
vital coefficient $a, b$ are 0.015 and $1.63 \times 10^{-10}$. Thus the population growth rate of Lakhshmipur is $1.5 \%$ per annum. According to this model, the population of Lakhshmipur is presumed to be 46150750 in the year 2275 . Logistic growth model calculated a carrying capacity for the Comilla's population to be 125050091.07 along with vital coefficients $\mathrm{a}, \mathrm{b}$ are respectively 0.016 and $1.28 \times 10^{-10}$. Thus the population growth rate of Comilla, regarding to this model, is $1.6 \%$ per annum which compares well with the statistically predicted values in literature. The population of Comilla will be 62525046 in the year 2205 .

The following are some recommendations: it can be seen that population of the above mentioned districts changes dramatically, so the government should work towards industrialization of these areas. Because industrialization solves accommodation problem and enhance food resource which will raise the carrying capacity of the environment by reducing coefficient $b$. Vital coefficient $a$ and $b$ ought to be re-valued frequently to estimate the alteration in population growth rate because these coefficients play an important role on economic developments, social trends, empirical advancement and Medicare obligations.. Because of the rapidly changing population various natural disasters may occur as the population exceeds environments carrying capacity. Government should take precautionary measures and facilitates planning for 'worst-case' outcome. This study introduces an important role for better sustainable development plans with the limited resources through the accurate idea of the future population size and related information of resources. Because future is intimately tied to the past, projection based on past trends and relationships raise our understanding of the dynamics of population growth and often provide forecasts of future population change that are sufficiently accurate to support good decision making. The projection of future population gives a future picture of population size which is controllable by reducing population growth with different possible measures. In the future to reduce regional or state level inequalities a comparative study like this will help the government in formulation the policy for identifying the thrust areas to be emphasized to improve the overall socio-economic development. Hence we hope this research work will help to build an evenly developed country.

\section{References}

[1] R. B. Banks. Growth and Diffusion Phenomena: Mathematical Frame works and Applications, Springer, Berlin, 1994.

[2] B. Martin. Differential equations and their applications 4th ed. ISBN 0-387-97894-1 Springer-Verlag, New York, 1992.

[3] H. Von Foerster. Some remarks on changing population, in "The Kinetics of Cell Cellular Proliferation", F. Stohlman Jr., Ed, Grune and Stratton, New York, 1959, pp. 387-407.

[4] M. J. Hossain, M. R. Hossain, D. Datta and M. S. Islam. "Mathematical Modeling of Bangladesh Population Growth". Journal of Statistics \& Management Systems Vol. 18(2015), No. 3, pp. 289-300, DOI: 10.1080/09720510.2014.943475.

[5] "Population and Housing Census 2011". Zila Report: Noakhali, Bangladesh Statistical Bureau, Bangladesh.

[6] "Population and Housing Census 2011". Zila Report: Feni, Bangladesh Statistical Bureau, Bangladesh.

[7] "Population and Housing Census 2011". Zila Report: Lakhshmipur, Bangladesh Statistical Bureau, Bangladesh.

[8] "Population and Housing Census 2011". Zila Report: Comilla, Bangladesh Statistical Bureau, Bangladesh.

[9] J. D. Murray. Mathematical Biology, Third Edition, Springer.

[10] A. Jafar. Differential equations and their applications, 2nd ed. Prentice Hall, New Delhi, 2004.

[11] F. R. Sharpe and A. J. Lotka. A problem in age distribution, Phil. Magazine, 21, 1911, pp. 435-438.

[12] A. Wali, D. Ntubabare and V. Mboniragira. Mathematical Modeling of Rwanda Population Growth: Journal of Applied Mathematical Sciences, Vol. 5(53), 2011, pp. 2617-2628.

[13] Plackett, R. L. (1972). The discovery of the method of least squares. Biometrika, 59, 239-251.

[14] Fred Brauer Carols Castillo-Chavez, Mathematical Models in Population Biology and Epidemiology, Springer, 2001. 